\title{
Distribution of Fos-like Immunoreactivity in the Medullary and Upper Cervical Dorsal Horn Produced by Stimulation of Dural Blood Vessels in the Rat
}

\author{
Andrew M. Strassman, Yoko Mineta, and Bart P. Vos \\ Department of Neurology, Massachusetts General Hospital and Harvard Medical School, Charlestown, Massachusetts \\ 02129
}

Neurophysiological studies have generally failed to find evidence of a specific ascending pathway for visceral nociception. However, pain that arises from deep or visceral tissues typically differs from cutaneous pain, particularly in its diffuse, poorly localized quality. In this study, the c-fos mapping technique was used in order to investigate possible differences in the distribution of central neurons activated by afferent pathways from cutaneous and deep tissues that may be related to the differing quality of the sensations they evoke. The distribution of neurons in the upper cervical and medullary dorsal horn that displayed fos-like immunoreactivity (fos-LI) was examined following mechanical stimulation of dural blood vessels (transverse and superior sagittal sinuses), and was compared to that found following mechanical, thermal, and chemical stimulation of facial sites.

Dural stimulation was carried out under Brevital anesthesia in rats that had received a chronic surgical exposure of the transverse and superior sagittal sinuses $2 \mathrm{~d}$ earlier. Localized mechanical stimulation of the dural surface of the transverse sinus produced a predominantly ipsilateral increase in the number of fos-LI neurons in the medullary and upper cervical dorsal horn (primarily laminae $I$ and V), and in the transition region between the trigeminal nucleus caudalis and interpolaris. Stimulation of the superior sagittal sinus produced increases in fos-LI labeling that were generally smaller than those produced by transverse sinus stimulation. The distribution of fos-LI labeling in the dorsal horn induced by dural stimulation differed from that induced by facial stimulation in two ways. (1) Dural stimulation produced a more diffuse distribution of fos-LI than facial stimulation in the dorsal horn. Whereas facial stimulation produced a dense, localized zone of fos-LI labeling in the dorsal horn, dural stimulation produced fos-LI labeling that extended from the midlevel of caudalis to $\mathrm{C2} / \mathrm{C3}$, and also extended across a large portion of the ventrolateral-to-dorsomedial axis of the dorsal horn. This distribution roughly corresponds to the representation of most of the dorsal half of the head and face. (2) Dural stimulation produced a more restricted laminar distribution of fos-LI labeling than facial stimulation, in

\footnotetext{
Received July 9, 1993; revised Nov. 10, 1993; accepted Nov. 24, 1993.

This work was supported by Grant NS24594 from the National Institute of Neurological Disorders and Stroke (NIH).

Correspondence should be addressed to Andrew Strassman, Department of Neurobiology, Harvard Medical School, 220 Longwood Avenue, Boston, MA 02115 .

Copyright (C) 1994 Society for Neuroscience $0270-6474 / 94 / 143725-11 \$ 05.00 / 0$
}

that the dural-induced labeling in the superficial dorsal horn was primarily restricted to lamina I, whereas facial stimulation typically induced substantial labeling in both lamina I and the outer part of lamina II. These differences in the central organization of the afferent pathways from dural and facial sites may contribute to the differences in the quality of sensations evoked by these pathways.

[Key words: trigeminal nucleus caudalis, migraine, vascular headache, meninges, nociception, pain]

Afferent signals that arise from deep or visceral structures converge centrally on nociceptive spinal neurons that also receive inputs from cutaneous sites (Pomeranz et al., 1968; Selzer and Spencer, 1969; Gokin, 1970; Hancock et al., 1973, 1975; Blair et al., 1981, 1984; Foreman et al., 1981; Milne et al., 1981; Cervero, 1982, 1983a,b; Ammons et al., 1983, 1984, 1985; Cervero and Tattersall, 1985, 1987; Honda, 1985; Ness and Gebhart, 1987, 1988, 1989; Bolser et al., 1991; Berkley et al., 1993; Euchner-Wamser et al., 1993). This central convergence of sensory inputs arising from superficial and deep tissues is thought to be the basis for the phenomenon of referred pain (Ruch, 1946), whereby afferent signals from deep tissues evoke sensations that are perceived as arising from a region of the body surface. In the unit recording studies cited above, nearly all of the visceral-responsive neurons that have been encountered, particularly those that were antidromically identified as projection neurons, could also be activated by stimulation of cutaneous and other somatic sites. Thus, available evidence does not support the existence of a specific ascending pathway for visceral nociception. However, visceral pain typically differs from cutaneous pain in several respects, particularly in having a diffuse, radiating, poorly localized quality. In the absence of a separate ascending pathway for visceral pain, the question arises of how nociceptive inputs from cutaneous and visceral sites can evoke sensations of such differing quality. Two possible explanations for such differences are that, although cutaneous and visceral inputs converge on the same central neurons, the patterns of central activity they evoke may differ in either their temporal or spatial characteristics.

The present study examined the second of these possibilities, a difference in the spatial patterns of central activation, for the afferent pathway originating from intracranial blood vessels, which is an example of a deep nociceptive input in the trigeminal system. Major intracranial blood vessels of the dura and pia receive a predominantly small-fiber afferent innervation from the trigeminal nerve (Huber, 1899; Penfield, 1932; Penfield and 
McNaughton, 1940; Feindel et al., 1960; Fang, 1961; Andres et al., 1987) that exhibits nociceptive properties similar to those found for other visceral tissues. Stimulation of these vessels in humans can evoke painful sensations that are typically referred to a region within the ipsilateral trigeminal dermatome (Fay, 1935; Feindel et al., 1960). This pain can be abolished by blockade of the trigeminal nerve or ganglion ipsilateral to the stimulus (Penfield and McNaughton, 1940). As with many visceral tissues, pain is the only sensation that can be evoked, regardless of whether the stimulation is electrical, mechanical, thermal, or chemical (Ray and Wolff, 1940). The nociceptive sensory innervation of intracranial blood vessels is thought to be involved in mediating the painful sensations of vascular headache syndromes such as migraine (Moskowitz, 1984; Moskowitz et al., 1988).

Retrograde tracing studies in the rat and cat have determined that the afferent innervation to the intracranial vasculature is primarily ipsilateral, and originates in the trigeminal ganglion and upper cervical dorsal root ganglia (C1-C3) (Mayberg et al., 1981, 1984; Steiger et al., 1982; Borges and Moskowitz, 1983; Keller et al., 1985; Arbab et al., 1986; O'Connor and van der Kooy, 1986; Hardebo et al., 1991). Unit recording studies in the cat have identified neurons in the medullary and upper cervical dorsal horn that can be activated by stimulation of major blood vessels of the intracranial dura (Davis and Dostrovsky, 1986, 1988a,b; Strassman et al., 1986; Lambert et al., 1992). Such dural-responsive neurons typically receive a convergent nociceptive input from a cutaneous facial receptive field, analogous to the somatic convergence found in visceral-responsive spinal neurons. Although some information is availablc from these microelectrode studies on the location of the duralresponsive neurons, the data are subject to sampling limitations and are not adequate for an analysis of the rostrocaudal or laminar distribution of dural-responsive neurons within the dorsal horn. The present study attempted to overcome some of these limitations of the unit recording data by using the $c$-fos mapping technique. Immunocytochemical detection of $c$-fos gene expression was used as a marker to investigate spatial patterns of neuronal activation in the medullary and upper cervical dorsal horn evoked by stimulation of dural blood vessels in the rat. The results were compared to the patterns of $\mathrm{c}$-fos labeling found with different forms of facial stimulation, in order to investigate potential differences in the central organization of afferent pathways originating from craniovascular and facial sites.

\section{Materials and Methods}

Surgery and dural stimulation. Adult male rats (250-350 gm) received a chronic surgical exposure of the transverse or superior sagittal sinus 2-4 d prior to dural stimulation. Rats were anesthetized with sodium pentobarbital $(55 \mathrm{mg} / \mathrm{kg}$ i.p.) and placed in a stereotaxic headholder. The dorsal surface of the skull was exposed through a midline incision. A portion of the left transverse sinus was exposed from the midline (sinus confluens) to about $4 \mathrm{~mm}$ lateral by removing the overlying bone with a dental drill. In some animals a segment of the superior sagittal sinus was exposed instead of the transverse sinus. The exposed segment of the sagittal sinus was approximately $5 \mathrm{~mm}$ in length, beginning approximately $2 \mathrm{~mm}$ rostral to the junction with the transverse sinus (the sinus confluens). This is a relatively caudal segment of the superior sagittal sinus, which has a total length of approximately $20 \mathrm{~mm}$. The exposed portions of the transverse and superior sagittal sinuses were similar in area (approximately $3.5-3.8 \mathrm{~mm}^{2}$ ). The exposed dural surface of the transverse or sagittal sinus was covered with bone wax, which adhered to the edge of the bone to form a water-tight seal over the dura. A cylindrical plastic chamber, $10 \mathrm{~mm}$ in diameter, was centered on the midline and cemented to the skull with dental acrylic. The placement of the chamber was the same in animals that received an exposure of either the transverse or sagittal sinuses, since the diameter of the chamber was large enough to include both exposures. The top of the chamber was sealed and the animals were given systemic antibiotics. Following surgery, animals were checked to verify that there were no signs of infection surrounding the surgical wound.

Two to $4 \mathrm{~d}$ following surgery, animals were anesthetized with Brevital (sodium methohexital, $35 \mathrm{mg} / \mathrm{kg}$ i.p.), and the bone wax was removed from the dura. The head was not placed in a stereotaxic frame, but was instead stabilized atraumatically by placing it in a mold of modeling clay. The animals then received one of three experimental treatments. (1) Control animals $(n=4)$, which had previously received an exposure of the transverse sinus, were maintained under anesthesia for $30 \mathrm{~min}$ with no stimulation. (2) Transverse sinus animals $(n-5)$ received 30 min of mechanical stimulation of the exposed transverse sinus that consisted of repeated stroking of the outer dural surface with a blunt forceps. (3) Sagillal sinus animals $(n=4)$ received the identical stimulation applied to the outer dural surface of the exposed superior sagittal sinus. All animals were maintained under Brevital anesthesia for a total of $30 \mathrm{~min}$, with supplemental injections as necessary, after which they were allowed to regain consciousness. Two hours later $(2.5 \mathrm{hr}$ after the induction of Brevital anesthesia), animals were given an overdose of pentobarbital and perfused as described below.

In preliminary experiments, urethane was initially used as an anesthetic, because it had been used in previous studies in this laboratory of fos-LI labeling induced by facial stimulation (Strassman and Vos, 1993; Strassman et al., 1993). After preliminary results showed a relatively low level of fos-LI labeling with dural stimulation compared to previous results with facial stimulation, it was decided to change to a short-acting anesthetic (Brevital) in an attempt to increase the labeling, based on the findings of Williams et al. (1990). The number of animals that received dural stimulation under urethane was too small for statistical analysis or comparison with Brevital, so only the results with dural stimulation under Brevital anesthesia are reported in this study. As described below, facial stimulation was studied with both urethane and Brevital anesthesia.

Facial stimulation. The results with dural stimulation are compared to those obtained with thermal, mechanical, and chemical forms of facial stimulation in urethane-anesthetized rats in previous studies. Thermal stimuli of $10^{\circ} \mathrm{C}(n=5)$ or $50^{\circ} \mathrm{C}(n=6)$ were applied to the vibrissal pad with a contact thermode in $30 \mathrm{sec}$ pulses that were delivered every $2 \mathrm{~min}$ for $30 \mathrm{~min}$ (Strassman et al., 1993). Mechanical stimulation consisted of repeated noxious pinch applied to the supraorbital skin ( 30 sec pinch applied once per minute for $15 \mathrm{~min}, n=4$ ) (Strassman and Vos, 1993) or repeated application of $2 \mathrm{gm}(n=5)$ or $15 \mathrm{gm}(n=5)$ von Frey hairs to the vibrissal pad for $30 \mathrm{~min}$ (Vos et al., 1991). Chemical stimulation consisted of repeated subcutaneous injection of $5 \%$ capsaicin (five injections of $10 \mu \mathrm{l}$ each in $15 \mathrm{~min}$ ) in the supraorbital region $(n=5)$. All animals were perfused $2 \mathrm{hr}$ after the end of the stimulation. Urethane produced a stable anesthesia that lasted for the duration of the $2 \mathrm{hr}$ survival period.

Since the dural stimulation was carried out under Brevital anesthesia, several animals were examined for the present study that received facial stimulation under Brevital anesthesia, in order to facilitate comparison with the dural stimulation animals. A total of three animals received noxious pinch as described above, which was applied to either the snout, the vibrissal pad, or the dorsum of the head (vertex) near the midline. In addition, a chemical stimulus that was not described in these previous studies, subcutaneous injection of formalin, was also used, and served to assess the effects of different anesthetics. Formalin injection is commonly used as a noxious test stimulus in behavioral studies, as well as in a number of fos-LI labeling studies. A single injection of $50 \mu 1$ of $5 \%$ formalin was made into the vibrissal pad of awake rats $(n=3)$ or rats anesthetized with either urethane $(n=3)$ or Brevital $(n=3)$. In order to make the survival period comparable to that of the other animals, the formalin-injected animals were perfused $2.5 \mathrm{hr}$ after the injection (since the formalin stimulus has an expected duration of $30-40 \mathrm{~min}$ ).

Although the fos-LI labeling obtained with most of these facial stimuli was described previously, the analysis described in the present study, of laminar distribution within the superficial dorsal horn (see below), was not reported previously for any of these facial stimuli except the thermal stimuli (Strassman et al., 1993).

Immunocytochemistry and data analysis. Tissue processing was done as described previously (Strassman and Vos, 1993). Two hours after the end of the stimulation, animals were given an overdose of pentobarbital and were perfused transcardially with saline followed by 900 
cc of $4 \%$ paraformaldehyde. The caudal medulla and upper cervical spinal cord (to $\mathrm{C} 3$ ) was removed as a single block and was cut transversely into $40 \mu \mathrm{m}$ frozen sections. Alternate sections were processed for fos immunocytochemistry with the avidin-biotin method. Sections were incubated for 1-2 $\mathrm{d}$ in a primary antiserum from Cambridge Research Biochemical (OA-1 1-823), which was raised in sheep against a synthetic peptide derived from the $\mathrm{N}$-terminal sequence of the c-fos protein. A biotinylated rabbit anti-sheep secondary antibody was then used, followed by incubation with the avidin-biotin-horseradish peroxidase complex, which was visualized with a nickel-intensified diaminobenzidine reaction.

For purposes of data analysis, the medullary and upper cervical dorsal horns were regarded as continuous and were divided into laminae I-V (Jacquin et al., 1986; Strassman and Vos, 1993). In the upper cervical spinal cord, lamina $\mathrm{V}$ was considered to be equivalent to the lateral reticulated area, a well-defined region that extends across the entire neck of the dorsal horn at upper ccrvical lcvels. In the caudal mcdulla, the lateral reticulated area expands to include all of the intermediate and ventral gray, and thus no longer corresponds to lamina V. At medullary levels, lamina $\mathrm{V}$ was considered to correspond to the lateral part of the reticular formation. The internal border of lamina $\mathrm{V}$ in the medulla is poorly defined in the rat and has not been indicated in previous studies; it has been indicated by a dashed line in the present study (cf. Fig. $1 F$ of Strassman and Vos, 1993). The region of the medullary reticular formation medially adjacent to lamina $\mathrm{V}$ was referred to as the intermediate zone of the reticular formation, after Paxinos and Watson (1986).

The caudal border of the trigeminal nucleus interpolaris was used as a reference point for rostrocaudal alignment between animals; this level was designated as 0.0 (Jacquin et al., 1986, 1988; Strassman and Vos, 1993). The region of the trigeminal nuclear complex immediately rostral to this level was referrcd to as the intcrpolaris/caudalis transition region $(\mathrm{Vi} / \mathrm{Vc})$, in which the alaminar nucleus interpolaris appears ventrolaterally and progressively disrupts the laminar borders of the medullary dorsal horn (nucleus caudalis). For purposes of analysis of cell distributions, $\mathrm{Vi} / \mathrm{Vc}$ was divided into a dorsal, intermediate, and ventral part as described in Strassman and Vos (1993).

Counts of fos-LI-labeled cells were made on alternate sections through the medullary and upper cervical dorsal horn (laminae I-II, laminae III-IV, and lamina V) and the $\mathrm{Vi} / \mathrm{Vc}$ region. Counting was done by an investigator who was blinded to the stimulus condition. For comparison of labeling in stimulated and control groups, the mean number of cells per section was calculated separately for the dorsal horn (from -1.6 to $-3.2 \mathrm{~mm}$ relative to interpolaris, including 21 sections) and the $\mathrm{Vi} / \mathrm{Vc}$ region (from 0.0 to $0.4 \mathrm{~mm}$ relative to interpolaris, including six sections). These levels were chosen in order to include the regions of peak labeling observed (post hoc) in stimulated animals. Peak labeling was calculated for the intermediate reticular formation and the nucleus of the solitary tract as the mean of the two sections between 0.0 and 0.8 with the greatest labeling (Strassman and Vos, 1993).

An additional analysis of the distribution of labeling within laminae I-II was carried out for comparison with previous results obtained with facial stimulation. For this calculation [proportion of cells in $\mathrm{I} /(\mathrm{I}+\mathrm{II})$ ], the mean of the four sections in each animal with the greatest number of labeled cells in laminae I-II was used, since this was the quantity that had been used in the previous study of thermal facial stimulation (Strassman et al., 1993).

One-way analysis of variance (ANOVA) was used with Duncan's post hoc comparison to investigate differences between groups (SUPERANOVA 1.1, Abacus Concepts). For the statistical comparison of proportions, a log-odds transformation was performed. The numbers of labeled cells ipsilateral and contralateral to the transverse sinus stimulation were compared with a paired, two-tailed $t$ test.

\section{Results}

\section{Transverse sinus stimulation}

Localized mechanical stimulation applied to the dural surface of the transverse sinus produced a relatively diffuse, widespread distribution of fos-LI-labeled cells in the upper cervical and medullary dorsal horn, which was predominantly ipsilateral to the stimulus (Figs. 1-3). Rostrocaudally, labeling in the dorsal horn extended over a fairly long distance, from rostral C3 or caudal $\mathrm{C} 2$ to the midlevel of the trigeminal nucleus caudalis (medullary dorsal horn) (Figs. $1 A-C, 2,3 C$ ). In the transverse plane, the labeling was most dense in the ventrolateral part of the dorsal horn, but usually extended dorsomedially across a substantial portion of the dorsal horn (Fig. 2; see Fig. $7 A$ ). This transverse distribution corresponds to the representation of the ophthalmic and part of the maxillary regions of the face. The dorsomedial part of the dorsal horn, representing the mandibular region, was relatively free of labeled cells.

In addition to this diffuse distribution of labeling in the dorsal horn, a separate, more restricted distribution of labeling was present further rostrally, in the transition region between the trigeminal nucleus interpolaris and caudalis $(\mathrm{Vi} / \mathrm{Vc}$ ) (Figs. $1 D$, $2,3 C$ ). These two rostrocaudally distinct distributions of labeling were separated by an interval of relatively little labeling, at rostral levels of caudalis (Figs. 2, 3C). Within $\mathrm{Vi} / \mathrm{Vc}$, labeled cells were concentrated ventrally and tended to cluster along the borders of, but not within, nucleus interpolaris (Fig. 2); this distribution corresponds to the pattern formed by the superficial laminae of the dorsal horn at this level (cf. Jacquin et al., 1988; Yoshida et al., 1991; Strassman and Vos, 1993).

Quantitative analysis showed that transverse sinus stimulation significantly increased the number of fos-LI cells above control values in the dorsal horn ( $p<0.001$, ANOVA; Duncan's post hoc comparison was used for all ANOVAs) and the Vi/Vc region $(p<0.01$, ANOVA) on the side ipsilateral to the stimulus (Fig. 4). The magnitudes of the increases were 11 -fold for the dorsal horn (laminae I-V, measured between -1.6 and -3.2 ) and 12-fold for the $\mathrm{Vi} / \mathrm{Vc}$ region (measured between 0.0 and $+0.4)$. Within the dorsal horn, labeling was significantly increased in laminae I-II ( 10 -fold, $p<0.01$, ANOVA) and lamina $\mathrm{V}$ (46-fold, $p<0.001$, ANOVA), but not in laminae III-IV. Within the $\mathrm{Vi} / \mathrm{Vc}$ region, labeling was significantly increased in the ventral part (13-fold, $p<0.05$, ANOVA), but not in the intermediate or dorsal parts (see Materials and Methods).

Smaller but significant increases in labeling above control levels were also present contralateral to the transverse sinus stimulation in the dorsal horn (laminae I-V, 2.7-fold increase, $p<0.05$, ANOVA) and Vi/Vc ( 5 -fold, $p<0.01$, ANOVA) (Fig. 4). Within the dorsal horn, the increase was significant only in lamina V ( 9 -fold, $p<0.01, \mathrm{ANOVA})$. The labeling was greater on the ipsilateral than the contralateral side for laminae I-II ( $p$ $<0.05)$, lamina $\mathrm{V}(p<0.01)$, and Vi/Vc $(p<0.05)$ (all paired $t$ tests, two tailed). The ratio of ipsilateral:contralateral labeling was $4.6 \pm 2.2$ (mean \pm SD) for the dorsal horn and $2.2 \pm 0.8$ for $\mathrm{Vi} / \mathrm{Vc}$. Some of the variability in the amount of contralateral labeling might be attributable to the fact that the stimulated dural area extended up to the midline, which has no clear demarcation on the surface of the transverse sinus.

Both control and stimulated animals showed bilateral labeling in the nucleus of the solitary tract, the inferior olive, and the intermediate zone of the reticular formation medial to lamina $\mathrm{V}$ (Fig. 2). Transverse sinus stimulation produced an increase in labeling above control levels in the intermediate reticular formation that was significant only on the ipsilateral side (3.7fold increase, $p<0.05$, ANOVA) (Fig. 4). Labeling in the nucleus of the solitary tract was slightly but not significantly increased by stimulation (Fig. 4). Labeling in the inferior olive was not analyzed quantitatively.

\section{Superior sagittal sinus stimulation}

Stimulation of a more rostral site on the dura, overlying the superior sagittal sinus (which is an unpaired midline structure), was generally less effective than transverse sinus stimulation in 

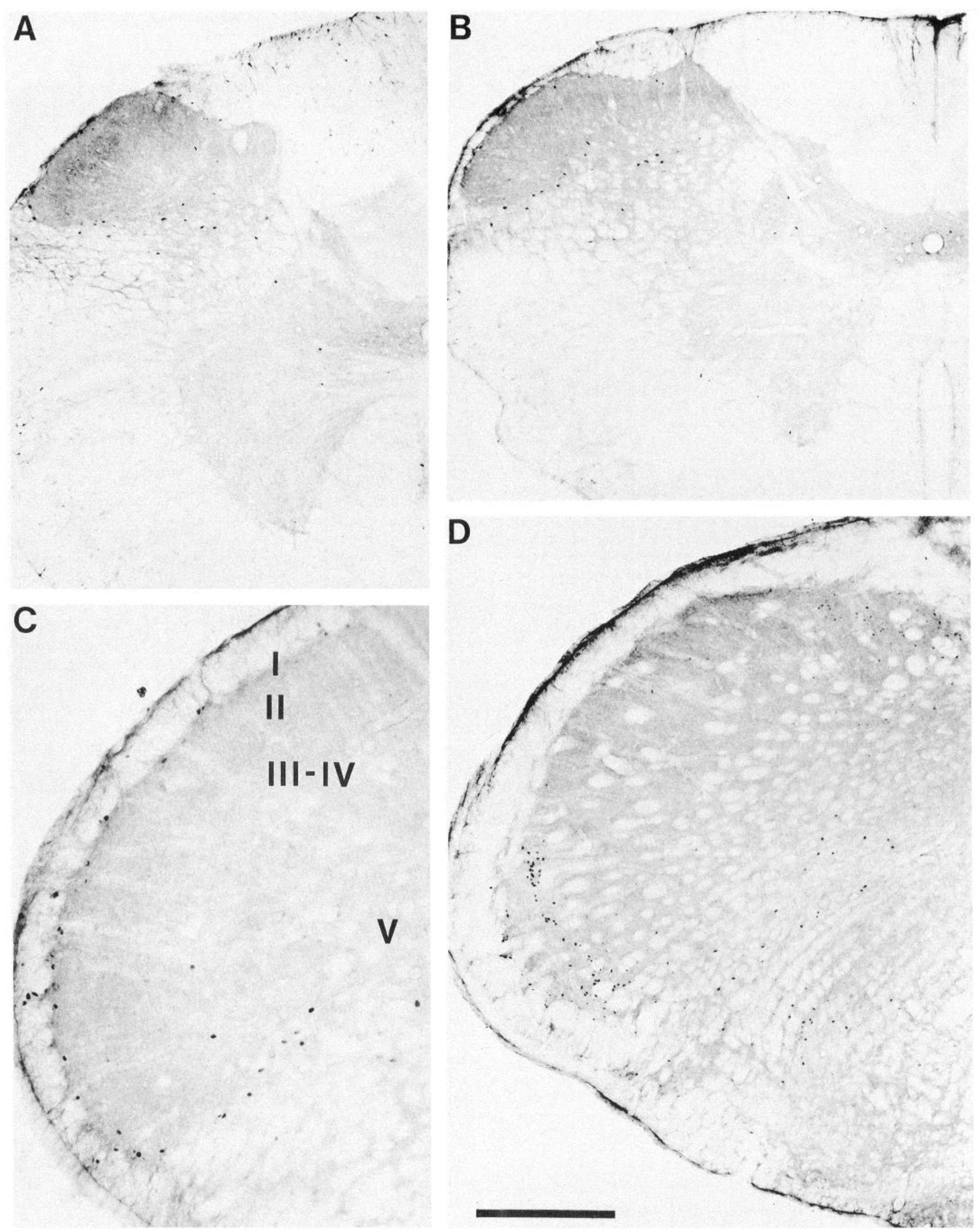

Figure 1. Photomicrographs of fos-LI cells in the caudal medulla and upper cervical spinal cord in animals that received mechanical stimulation of the dura (transverse sinus). Each photomicrograph shows the left side, which is ipsilateral to the stimulus. $A$, Rostral C3 spinal cord. $B$, Rostral $\mathrm{C} 2$ spinal cord. $C$, Caudal level of the trigeminal nucleus caudalis. $D$, Transition region between the trigeminal nucleus caudalis and interpolaris $(\mathrm{Vi} / \mathrm{Vc}$ ), approximately $160 \mu \mathrm{m}$ rostral to the caudal border of interpolaris (comparable to the most rostral section in Fig. 2). Scale bar: $500 \mu \mathrm{m}$ for $A, B$, and $D ; 250 \mu \mathrm{m}$ for $C$. 

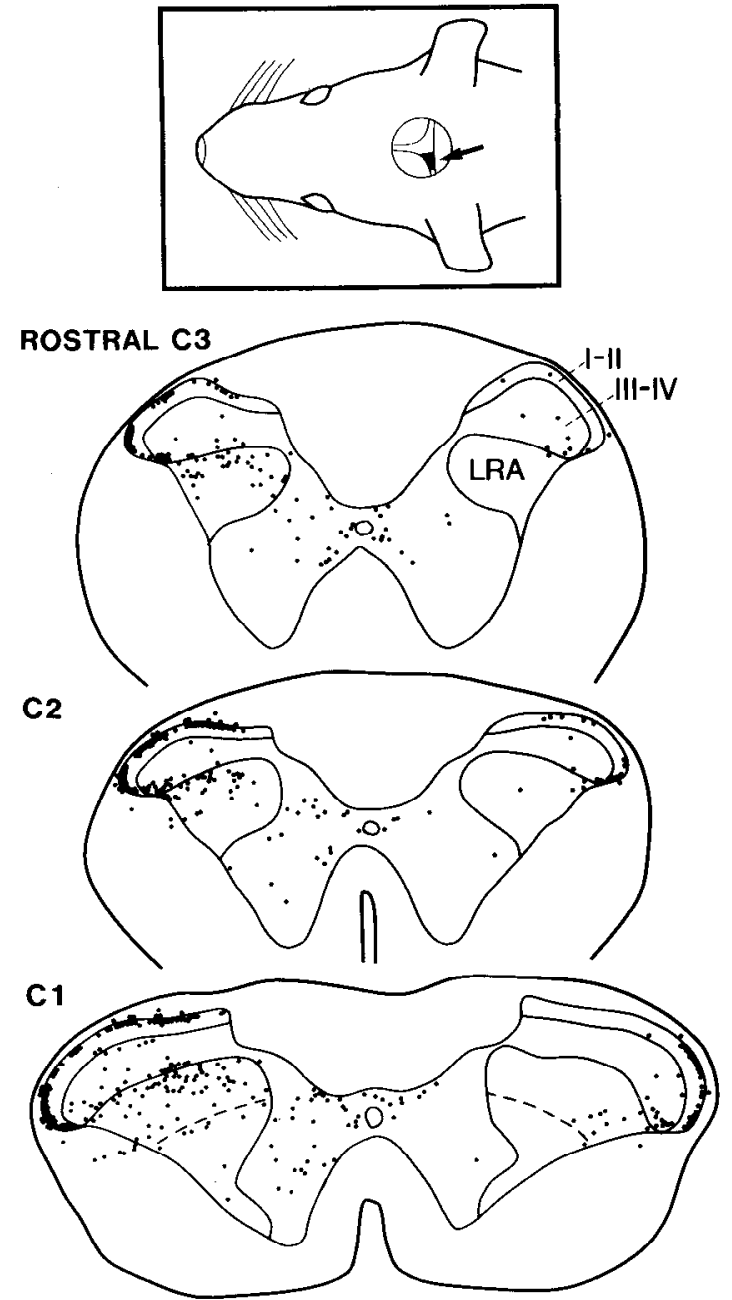
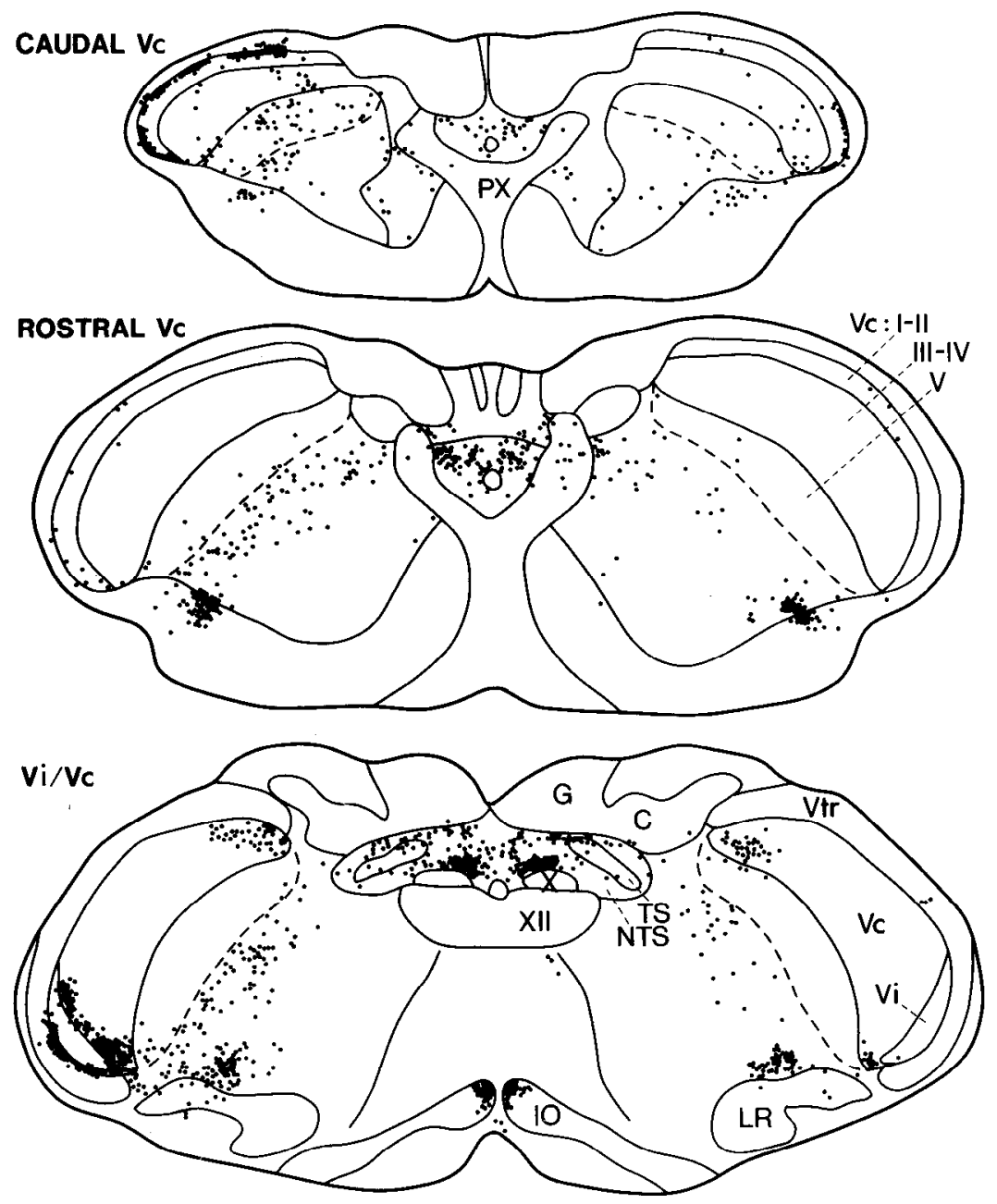

Figure 2. Reconstruction of the locations of fos-LI cells in an animal that received dural (transverse sinus) stimulation. Transverse sections are shown from caudal to rostral through the upper cervical spinal cord and caudal medulla. The left side of each section is ipsilateral to the stimulus. Each drawn section plots the location of cells from six consecutive alternate $40 \mu \mathrm{m}$ sections, except for the most rostral section (Vi/Vc), which contains the cells from three $40 \mu \mathrm{m}$ sections. $I-V$, laminae of the dorsal horn; $V c$, trigeminal nucleus caudalis; $V i$, trigeminal nucleus interpolaris; $V t r$, trigeminal tract; $X$, dorsal motor nucleus of the vagus; $X I I$, hypoglossal nucleus; $C$, cuneate nucleus; $G$, gracile nucleus; $I O$, inferior olive; $L R$, lateral reticular nucleus; $L R A$, lateral reticulated area; $N T S$, nucleus of the solitary tract; $P X$, pyramidal decussation; $T S$, solitary tract.

producing fos-LI labeling (Fig. 4). Sagittal sinus stimulation produced smaller but significant increases in labeling above control levels in the dorsal horn (2.5-fold, $p<0.05$, ANOVA) and $\mathrm{Vi} / \mathrm{Vc}$ (4-fold, $p<0.05$, ANOVA). Within the dorsal horn, the increase was significant only for lamina V (11-fold, $p<0.01$, ANOVA). The labeling produced by transverse sinus stimulation (mean of left and right sides) was significantly greater than that produced by sagittal sinus stimulation in both the dorsal horn and $\mathrm{Vi} / \mathrm{Vc}(p<0.05$, ANOVA $)$.

\section{Comparison with facial stimulation}

A rostrocaudal plot of the fos-LI labeling in the dorsal horn produced by dural stimulation revealed a flatter, more even distribution than that produced by localized mechanical stimulation of facial sites (Fig. 5). The distribution of labeling produced by dural stimulation was also more diffuse in the transverse plane, with a greater extent along the ventrolatcral-todorsomedial axis, compared with that produced by facial stimulation (see Fig. 7 and Strassman and Vos, 1993). Based on the distributions of fos-LI labeling produced by localized facial stimulation (Fig. 5 and Strassman and Vos, 1993), it appears that the distribution in the dorsal horn produced by dural stimulation roughly corresponds to the representation of most of the ophthalmic and maxillary territory of the face from the intraaural line to the rostral part of the vibrissal pad (Fig. 6).

The laminar distribution of dorsal horn labeling produced by dural stimulation also differed from that found with facial stimulation. Whereas noxious facial stimulation produced substantial labeling in both lamina I and outer lamina II, dural stimulation produced labeling in the superficial dorsal horn that was primarily restricted to lamina I (Figs. 7, 8). The proportion of superficial dorsal horn labeling in laminae I was significantly greater with dural stimulation than with several forms of facial stimulation, including noxious heat $\left(50^{\circ} \mathrm{C}\right)$, capsaicin, formalin, noxious pinch, or von Frey hair stimulation (15 gm and $2 \mathrm{gm}$ ) (all $p<0.01$, ANOVA) (Fig. 8). The only form of facial stimulation that produced a similarly high proportion of labeling in lamina I was $10^{\circ} \mathrm{C}$ cold stimulation.

As explained in Materials and Methods, the facial stimulation was done under urethane anesthesia, whereas the dural stimulation was done under Brevital anesthesia. Therefore, the difference between dural and facial stimulation illustrated in Figure 


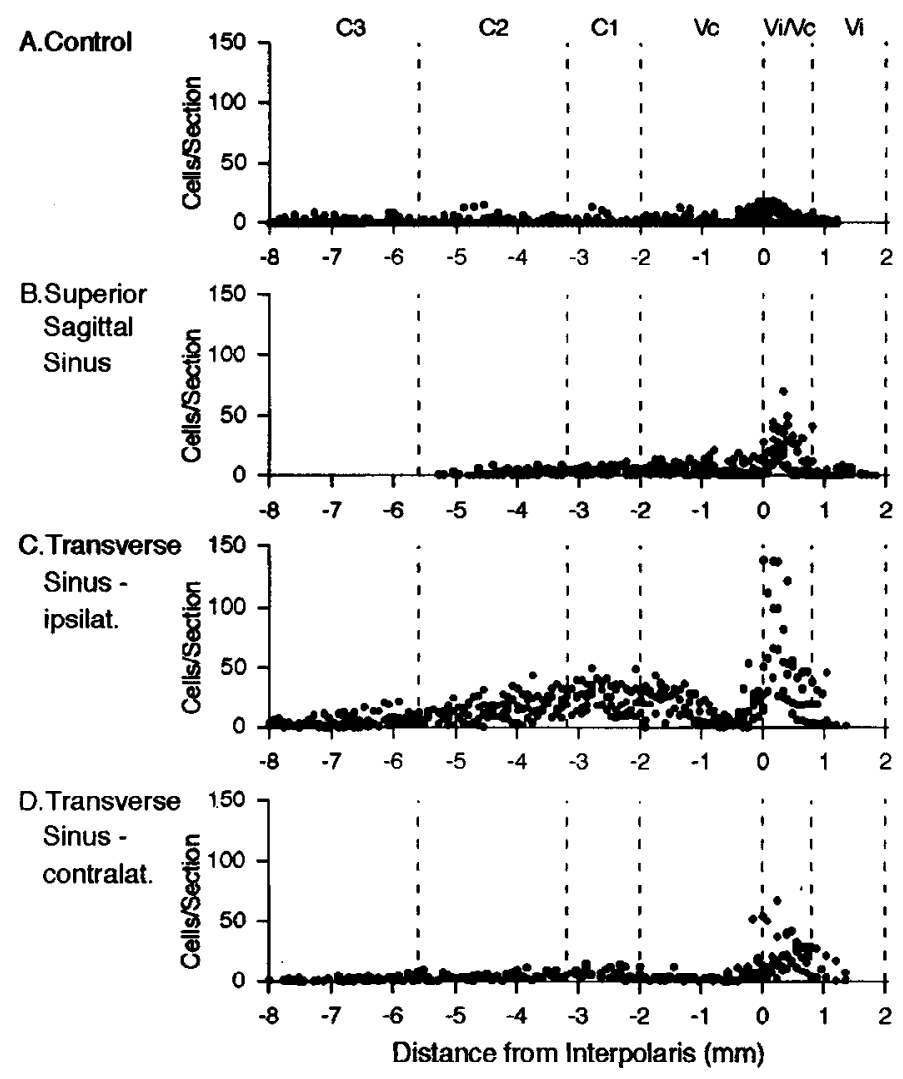

Figure 3. Plots of the rostrocaudal distribution of the number of fosLI cells in the dorsal horn (laminae I-V) and trigeminal complex in the unstimulated control animals $(A ; n=4)$ and in animals that received mechanical stimulation of the superior sagittal sinus $(B ; n=4)$ or transverse sinus $(C, D ; n=5)$. Labeling position is shown relative to the caudal border of the trigeminal nucleus interpolaris (see Materials and Methods). Each plot shows the counts for all of the animals in that group. Each dot represents the number of cells on one side of one section. In $A$ and $B$, cell counts for the left and right sides are shown on a single plot (as separate dots). In $C$ and $D$, cell counts for the sides ipsilateral and contralateral to the transverse sinus stimulus are shown on separate plots.

8 may be at least partly a consequence of the difference in anesthesia. In order to assess the effects of these anesthetics on the laminar distribution in the superficial dorsal horn, one of the facial stimuli, formalin, was also studied in Brevital-anesthetized animals and in unanesthetized animals. There was no significant difference between the three groups in the proportion of labeling in lamina I (all $p>0.4$, ANOVA). The value of this proportion for the urethane, Brevital, and unanesthetized animals was $0.40 \pm 0.03,0.40 \pm 0.02$, and $0.47 \pm 0.09$, respectively (mean $\pm \mathrm{SD}$ ).

\section{Discussion}

This study used the c-fos mapping technique to compare the spatial patterns of neuronal activation evoked by dural and facial stimulation in the medullary and upper cervical dorsal horn. The use of fos-LI as a cellular marker for physiological activation in the trigeminal system was evaluated in a previous study (Strassman and Vos, 1993), which also discussed some of the uncertainties associated with the physiological interpretation of fos-LI labeling. Although exceptions may be found in the future, the results of this previous study as well as other in vivo studies in a variety of central pathways have generally been

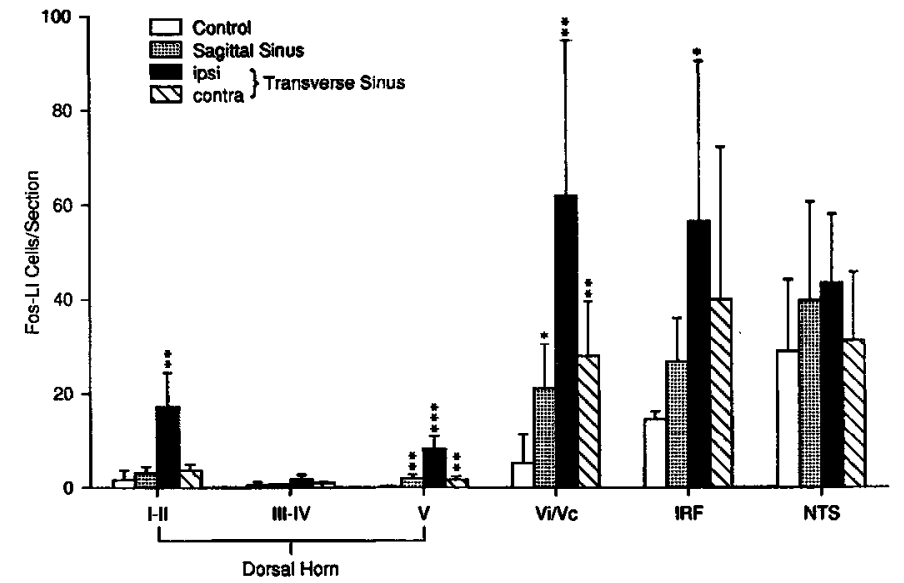

Figure 4. Histogram comparing the mean number of fos-LI cells in control animals and in animals that received stimulation of the superior sagittal sinus or transverse sinus. Separate counts of labeled cells are shown for dorsal horn laminae I-II, III-IV, and V, and for the interpolaris/caudalis transition region $(V i / V c)$, the nucleus of the solitary tract $(N T S)$, and the intermediate reticular formation $(I R F)$, which includes the ventrolateral medulla. Dorsal horn labeling was calculated as the mean labeling per section between -1.6 and $-3.2 \mathrm{~mm}$ relative to the caudal border of interpolaris (compare Fig. 3); Vi/Vc labeling was calculated as the mean labeling between 0.0 and +0.4 . Counts for control and superior sagittal sinus animals represent the mean of the left and right sides, while counts for the ipsilateral and contralateral sides of transverse sinus animals are shown separately. Asterisks indicate significant differences compared to the control group: ${ }^{*},{ }^{* *}$, and ${ }^{* * *}, p$ $<0.05,0.01$, and 0.001 , respectively (ANOVA, Duncan's post hoc comparisons). Mean $+\mathrm{SD}$.

consistent with the idea that the presence of fos-LI can be regarded as evidence of physiological activation, particularly at short survival times following stimulation (1-3 hr); longer survival times can result in labeling patterns that cannot be readily explained in terms of physiological activation (Williams et al., 1990).

A limitation of the present study is that the anesthetic used for dural stimulation (Brevital) was different from that used in the previous studies on facial stimulation (urethane) from which most of the data for comparison are taken. This issue was partly addressed in the present study by examining fos-LI labeling in a small number of animals in which facial stimulation was delivered under Brevital anesthesia. Comparison with the results oblained with the same types of facial stimulation under urethane anesthesia indicated that the difference in anesthetic had no discernible effect on those aspects of somatotopic or laminar distribution that were analyzed in the present study.

An additional limitation of the present study is that it did not compare the effects of different types of dural vascular stimuli, but rather relied on a single, relatively nonphysiological mechanical stimulus, stroking of the outer surface of the dural venous sinuses. This stimulus has some advantages for the purposes of the present study compared with more physiologically relevant stimuli such as intravascular distention or injection of algesic or inflammatory chemicals: (1) it involves minimal surgical intervention, head stabilization, or tissue damage, which could increase the background labeling and complicate the interpretation of the results; and (2) it is well localized and so can be restricted to a specified dural location without risk of stimulus spread to nondural tissues.

The results of the present study show that localized dural stimulation produces a distinctive pattern of fos-LI labeling in 


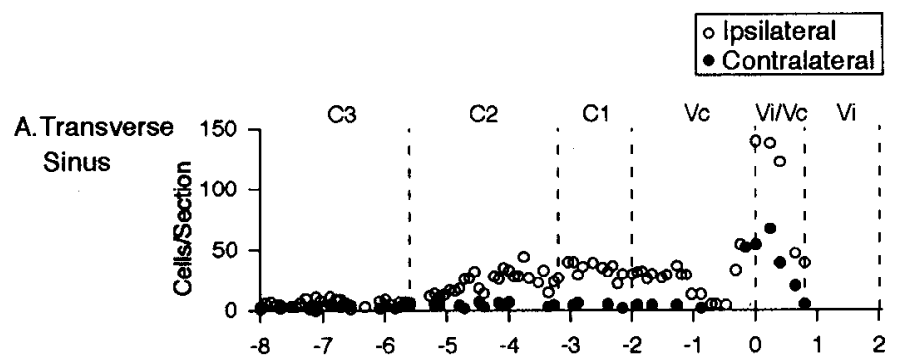

B.Snout
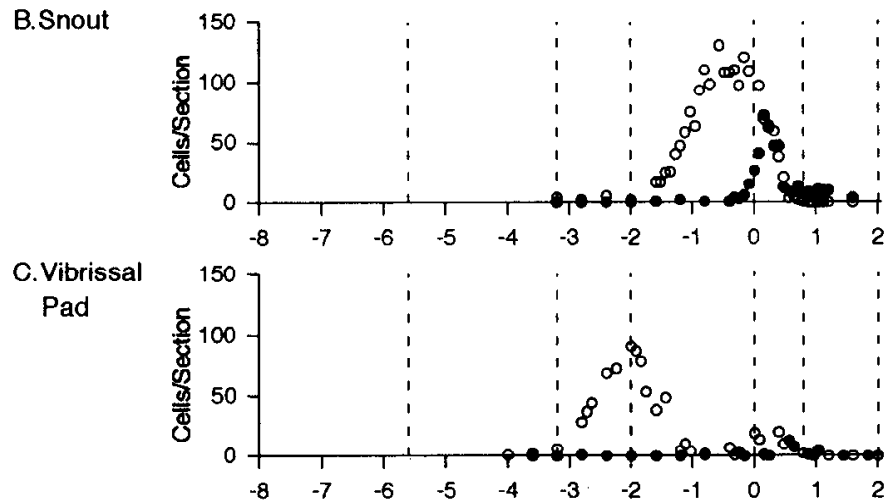

D. Vertex

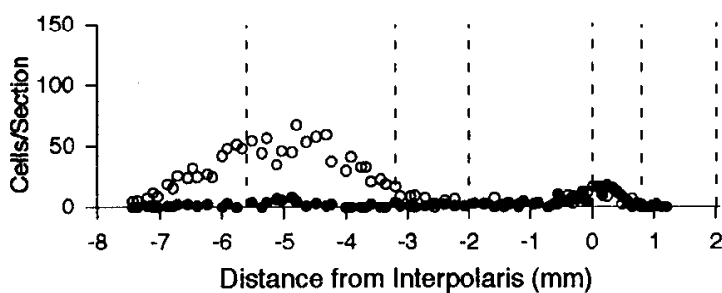

Figure 5. Plots of the rostrocaudal distribution of the number of fosLI cells in the dorsal horn (laminae I-V) and trigeminal complex in animals that received dural or facial stimulation. All animals were stimulated under Brevital anesthesia. $A$, Mechanical stimulation of the transverse sinus (stroking the dural surface with a blunt probe). $B$, Noxious pinch applied to the rostral tip of the snout (rhinarium). $C$, Noxious pinch applied to the skin at the base of the D-E vibrissa (the most ventrocaudal mystacial vibrissa). $D$, Noxious pinch applied to the skin location approximately overlying the transverse sinus, on the dorsum of the head (vertex), at the level of the intra-aural line, approximately $2 \mathrm{~mm}$ off the midline (see figurine in Fig. 2). Each plot shows the data for one animal. Each data point represents the number of cells counted on one section. Counts for the ipsilateral and contralateral sides are represented by open and solid circles, respectively.

the dorsal horn that differs in some respects from that produced by noxious facial stimulation. The dependence of the duralinduced labeling on the dural stimulation itself, rather than on nonspecific effects associated with the experimental paradigm, is supported by several observations: (1) the labeling produced by dural stimulation was significantly greater than that found in control animals, in both the dorsal horn and the $\mathrm{Vi} / \mathrm{Vc}$ region; (2) the amount of labeling was dependant on the stimulus location, in that the labeling produced by transverse sinus stimulation was greater on the side ipsilateral to the stimulus, and was also greater than that produced by sagittal sinus stimulation. The greater effectiveness of the transverse sinus stimulation may be an indication of a greater innervation density in that portion of the supratentorial dura, which lies more proximally along the course of the tentorial nerve.

The finding of a dense distribution of fos-LI-labeled cells in the $\mathrm{Vi} / \mathrm{Vc}_{\mathrm{c}}$ region is of particular interest in view of previous observations of fos-LI labeling specifically distributed in this

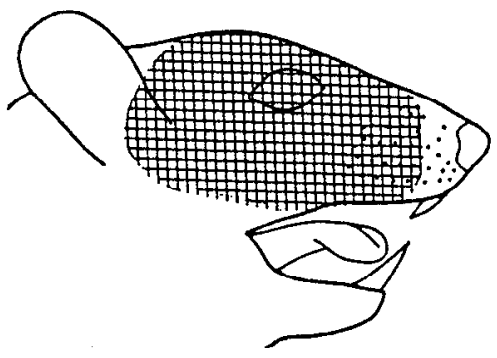

Figure 6. Approximate extent of the facial region whose brainstem representation overlaps that of the dura, as determined by comparing the transverse and rostrocaudal distributions of fos-LI labeling in the dorsal horn produced by dural stimulation with that produced by stimulation of various facial sites (Fig. 5; see also Strassman and Vos, 1993).

region following corneal stimulation and urethane anesthesia (Lu et al., 1993; Strassman and Vos, 1993). These findings raise the possibility that this restricted region of the trigeminal complex may have a distinctive role in visceral and facial nociceptive function.

Previous studies have shown that urethane anesthesia can induce fos-LI in two medullary autonomic centers, the nucleus of the solitary tract and the intermediate reticular formation (which includes the ventrolateral medulla) (Krukoff et al., 1992; Strassman and Vos, 1993); the fos induction in these regions may be related to the autonomic perturbations that can accompany urethane anesthesia. The present results showed that Brevital-anesthetized animals also exhibit fos-LI labeling in these two regions, as well as in one additional medullary region, the inferior olive, which does not show labeling with urethane anesthesia. As was found previously with facial stimulation, (Strassman and Vos, 1993), dural stimulation produced a moderate increase in the number of fos-LI labeled cells in the intermediate reticular formation, and no significant increase in the nucleus of the solitary tract. The failure of either dural or facial stimulation to produce a significant increase in the nucleus of the solitary tract in these studies is inconclusive, because of the relatively high background labeling present in the control animals. If noxious stimuli did in fact induce fos expression in this region, but in the same population of cells that is labeled by anesthesia, then no further increase in the number of labeled cells would be expected with stimulation. This possibility represents a major limitation in the interpretation of fos labeling for any region that shows substantial background labeling.

\section{Comparison with facial stimulation}

The present study found that the distribution of fos-LI labeling in the dorsal horn induced by localized dural stimulation differed from that induced by localized facial stimulation in two ways.

(1) Dural stimulation produced a more diffuse distribution of fos-LI than facial stimulation along the somatotopic (rostrocaudal and ventrolateral-to-dorsomedial) axes of the dorsal horn. Facial stimulation produces a dense, localized zone of fos-LI labeling in the dorsal horn whose position varies predictably with the rostrocaudal and dorsoventral position of the stimulation site (Strassman and Vos, 1993). In contrast, dural stimulation produced fos-LI labeling in the dorsal horn that is fairly evenly distributed across a widespread area that extends from the midlevel of caudalis to $C 2 / C 3$, and also extends across a large portion of the ventrolateral-to-dorsomedial axis of the dorsal horn. This distribution corresponds approximately to the 


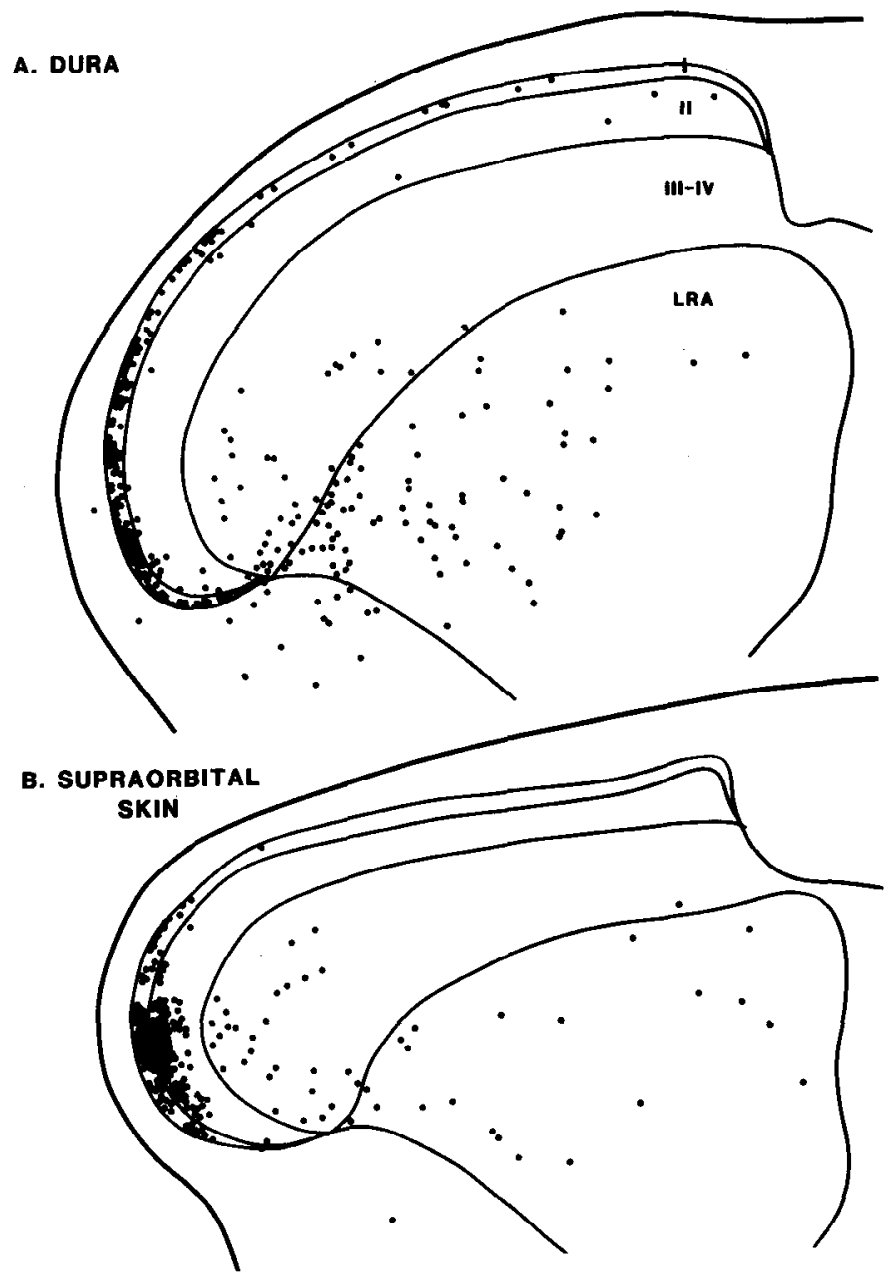

Figure 7. Laminar distribution of fos-LI labeling produced by dural and facial stimulation. $A$ and $B$, Reconstruction of the locations of fosLI-labeled cells in the dorsal horn following mechanical stimulation of transverse sinus (stroking the dural surface with a blunt probe; $A$; cells plotted from ten $40 \mu \mathrm{m}$ sections) and supraorbital skin (noxious pinch of the skin surrounding the supraorbital vibrissae; $B$; cells plotted from three $40 \mu \mathrm{m}$ sections).

representation of most of the dorsal half of the head and face, which is roughly comparable to the region of pain referral produced by stimulation of the supratentorial dura in humans (Ray and Wolff, 1940).

(2) Dural stimulation produced a more restricted laminar distribution of fos-LI labeling than facial stimulation, in that the dural-induced labeling in the superficial dorsal horn was primarily restricted to lamina I, while facial stimulation typically induced labeling in both lamina I and the outer part of lamina II.

Both of these features of the dural-induced fos-LI distribution-a widespread distribution and a relative absence of labeling in lamina II-are characteristic of visceral afferent pathways in the spinal cord. The central projections of visceral nerves typically have a widespread rostrocaudal and mediolateral distribution in the spinal dorsal horn. For example, the afferent projections of the renal nerve in the cat are distributed rostrocaudally over nine spinal segments, and extend across virtually the entire mediolateral extent of the superficial dorsal horn (Kuo et al., 1983). Within the superficial dorsal horn, the primary afferent fibers of most visceral organs terminate primarily in

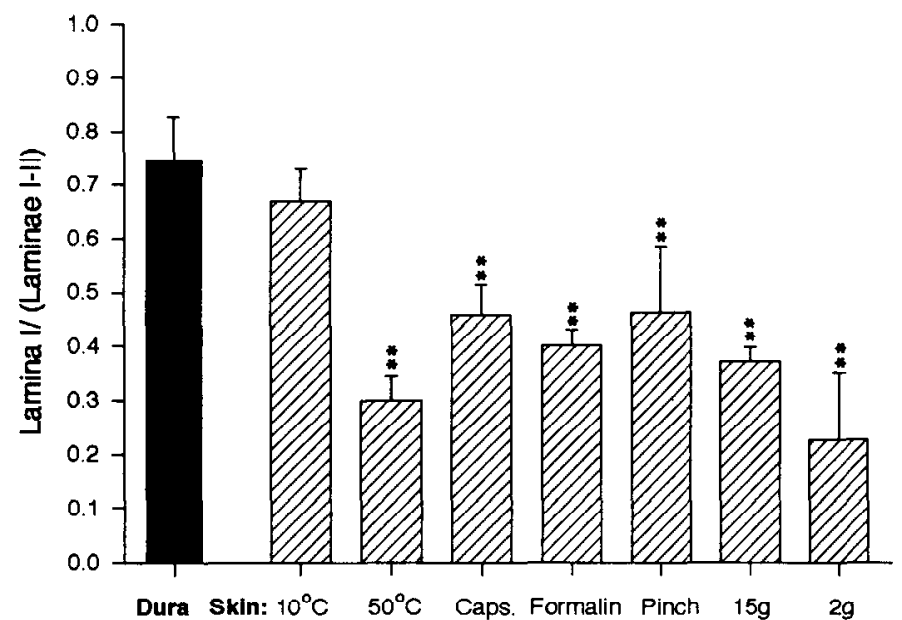

Figure 8. Histogram comparing the laminar distribution of labeling in the superficial dorsal horn (laminae I-II) for dural and facial stimulation, expressed as the proportion of labeling in lamina I, or I/(I-II). Asterisks indicate significant differences compared to the dural stimulation group: ${ }^{* *}, p<0.01$ (log-odds transformation; ANOVA, Duncan's post hoc comparisons). Mean + SD. The proportion of labeling in lamina I produced by dural stimulation was significantly greater than that produced by all of the cutaneous stimuli except $10^{\circ} \mathrm{C}$.

lamina I, with almost no projection to lamina II; this restricted laminar distribution has been found for the renal, hypogastric, pelvic, splanchnic, lumbocolonic, and inferior cardiac nerves (Morgan et al., 1981, 1986a,b; Ciriello and Calaresu, 1983; Kuo et al., 1983, 1984; Nadelhaft et al., 1983; Cervero and Connell, 1984a,b; Nadelhaft and Booth, 1984; Kuo and De Groat, 1985). Similar results have also been found with intracellular labeling of single visceral afferent fibers (Sugiura et al., 1989, 1993; Mizumura et al., 1993). A similar paucity of afferent projections to lamina II has also been found for the afferent innervation of other deep tissues, including muscle (Nyberg and Blomqvist, 1984; Mense and Craig, 1988; Shigenaga et al., 1988) and joint (Craig et al., 1988). This projection pattern of deep and visceral afferents contrasts with that of cutaneous afferents, which terminatc heavily in both laminac I and II (c.g., Jacquin et al., 1983; Shigenaga et al., 1986; Woolf and Fitzgerald, 1986; LaMotte et al., 1991; Sugiura et al., 1993).

This differential distribution of visceral and cutaneous afferents appears to be reflected in the response properties of neurons in lamina I and II of the spinal dorsal horn. Although it can be difficult to distinguish between lamina I and II with extracellular microelectrode localization lechniques such as electrolytic lesions or micrometer readings, Cervero has used the more precise method of dye ejection to provide evidence that visceral-responsive neurons are located in lamina I but not in II (Cervero, 1983a,b; Cervero and Tattersall, 1985). Similar results have been obtained in a number of $\mathrm{c}$-fos mapping studies of visceral pathways, which found increased labeling in lamina I, with little or no increase in lamina II, following intraperitoneal injection of acetic acid (Menetrey et al., 1989) or vaginocervical mechanostimulation (Chinapen et al., 1992). However, other forms of visceral stimulation have been found to produce substantial fos-LI labeling in both lamina I and II, including colorectal distention (Traubet al., 1992) and urinary tract irritation (Birder and de Groat, 1992). It is possible that the lamina II labeling found in these latter studies may result from the catheterization 
procedure, rather than from the visceral stimulus itelf; alternately, it may reflect a fundamental difference in the spinal organization of these visceral afferent pathways.

In the present study, the use of a chronic exposure was critical for minimizing the labeling in control animals and thus allowing a more accurate determination of the laminar distribution of the stimulus-induced labeling. The distribution of labeling primarily in lamina I and $\mathrm{V}$ suggests that the dural afferent input to the upper cervical and medullary dorsal horn may exhibit a similar laminar distribution to that of visceral afferent inputs to the spinal dorsal horn. However, evidence from other techniques to corroborate this point is lacking. Attempts to determine directly the central distribution of dural primary afferent terminations have not yet been successful, due to the difficulty of obtaining transganglionic transport in this afferent pathway. Unit recording studies of dural-responsive neurons in the dorsal horn have provided only limited information on the distribution of these neurons. Such neurons have been found almost entirely in the deep part of the dorsal horn (laminae III-V) (Davis and Dostrovsky, 1988), but this is almost certainly a reflection of the greater difficulty of obtaining recordings from neurons in the superficial laminae. A relative scarcity of neurons sampled from the superficial laminae is also apparent in other unit recording studies of brainstem trigeminal neurons with convergent inputs from deep tissues (Amano et al., 1986; Sessle et al., 1986; Broton et al., 1988). The ability of the fos-LI mapping technique to overcome the sampling limitations of microelectrode studies has thus provided information on the distribution of convergent neurons in the superficial medullary dorsal horn that could not be readily obtained with other techniques.

Fos-LI labeling has been used previously to investigate central pathways responsive to intracranial meningeal stimulation (Nozaki et al., 1992a,b; Moskowitz et al., 1993). In these studies, fos-LI labeling was induced in the medullary and upper cervical dorsal horn by injection of blood or carragecnan into the intracranial subarachnoid space (Nozaki et al., 1992a,b), or by induction of spreading depression in the cerebral cortex (Moskowitz et al., 1993). In contrast to the present results with dural stimulation, these more diffuse forms of intracranial stimulation induced substantial labeling in lamina II that was at least as great as if not greater than that in lamina I. As with the visceralinduced fos-LI labeling results ciled above (Birder and deGroat, 1992; Traub et al., 1992), it is possible that the substantial lamina II labeling may be partly attributable to the surgical procedures required to deliver these stimuli, rather than the intracranial stimulus itelf; alternately, it may reflect a difference in the central organization of the afferent pathways originating from dural and subarachnoid tissues.

The relative absence of an input to lamina II exhibited by the afferent pathways from the dura and other deep and visceral tissues may represent a fundamental difference from cutancous pathways in the central processing of sensory information. The restricted laminar distribution of dural and visceral-responsive neurons in the dorsal horn indicates a difference from cutaneous pathways not only in the distribution of primary afferent terminations but also in the intrinsic circuitry of the dorsal horn. In cutaneous pathways, primary afferent inputs to lamina I (A $\delta$ nociceptors, Light and Perl, 1979) can activate lamina II neurons (Light et al., 1979; Price et al., 1979; Bennett et al., 1980; Woolf and Fitzgerald, 1983; Light and Kavookjian, 1988), presumably through interneuronal connections or dendritic extensions into lamina I. In contrast, the laminar specificity exhibited in the termination pattern of visceral primary afferents appears to be preserved in the intrinsic circuitry of the dorsal horn.

The differential input to lamina II from cutaneous and deep tissues could be of importance for the control of sensory transmission because lamina II consists almost entirely of interneurons (Szentagothai, 1964), many of which contain GABA (Hunt et al., 1981; Carlton and Hayes, 1990; Todd and Sullivan, 1990) and are thought to be inhibitory. The relative lack of an afferent input to lamina II could result in a reduced ability to engage the inhibitory mechanisms that typically accompany cutaneous afferent input. Such a reduction of inhibition might contribute to the more diffuse distribution of neuronal activation in the dorsal horn evoked by inputs from deep tissues. Both a reduced level of lamina II-mediated inhibition and the more diffuse spatial pattern of neuronal activation might be related to some of the distinctive features that characterize both dural and visceral pain, such as the diffuse, radiating quality.

\section{Note added in proof}

A recent report has described similar results with electrical stimulation of the superior sagittal sinus in the cat (Kaub et al., Brain Research 629:95-102, 1993).

\section{References}

Amano N, Hu JW, Sessle BJ (1986) Responses of neurons in feline trigeminal subnucleus caudalis (medullary dorsal horn) to cutaneous, intraoral, and muscle afferent stimuli. J Neurophysiol 55:227-243.

Ammons WS, Blair RW, Foreman RD (1983) Vagal afferent inhibition of primate thoracic spinothalamic neurons. J Neurophysiol 50:926940.

Ammons WS, Blair RW, Foreman RD (1984) Greater splanchnic excitation of primate $T_{1}-T_{S}$ spinothalamic neurons. $J$ Neurophysiol 51:592-603.

Ammons WS, Girardot M-N, Foreman RD (1985) $T_{2}-T_{3}$ spinothalamic neurons projecting to medial thalamus with viscerosomatic input. J Neurophysiol 54:73-89.

Andres KH, von During M, Muszynski K, Schmidt RF (1987) Nerve fibres and their terminals of the dura mater encephali of the rat. Anat Embryol (Berl) 175:289-301.

Arbab MAR, Wiklund L, Svendgaard NA (1986) Origin and distribution of cerebral vascular innervation from superior cervical, trigeminal and spinal ganglia investigated with retrograde and anterograde WGA-HRP tracing in the rat. Neuroscience 19:695-708.

Bennett GJ, Abdelmoumene MA, Hayashi H, Dubner R (1980) Physiology and morphology of substantia gelatinosa neurons intracellularly stained with horseradish peroxidase. J Comp Neurol 194:809_ 827.

Berkley KJ, Hubscher CH, Wall PD (1993) Neuronal responses to stimulation of the cervix, uterus, colon, and skin in the rat spinal cord. J Neurophysiol 69:545-556.

Birder LA, de Groat WC (1992) Increased c-fos expression in spinal neurons after irritation of the lower urinary tract in the rat. $J$ Neurosci $12: 4878-4889$.

Blair RW, Weber RN, Foreman RD (1981) Characteristics of primate spinothalamic tract neurons receiving viscerosomatic convergent inputs in $T_{3}-T_{5}$ segments. J Neurophysiol 46:797-811.

Blair RW, Ammons WS, Foreman RD (1984) Responses of thoracic spinothalamic and spinoreticular cells to coronary artery occlusion. J Neurophysiol 51:636-648.

Bolser DC, Hobbs SF, Chandler MJ, Ammons WS, Brennan TJ, Foreman RD (1991) Convergence of phrenic and cardiopulmonary spinal afferent information on cervical and thoracic spinothalamic tract neurons in the monkey: implications for referred pain from the diaphragm and heart. J Neurophysiol 65:1042-1054.

Borges LF, Moskowitz MA (1983) Do intracranial and extracranial trigeminal afferents represent divergent axon collaterals? Neurosci Lett 35:265-270.

Broton JG, Hu JW, Sessle BJ (1988) Effects of temporomandibular joint stimulation on nociceptive and nonnociceptive neurons of the 
cat's trigeminal subnucleus caudalis (medullary dorsal horn). J Neurophysiol 59:1575-1589.

Carlton SM, Hayes ES (1990) Light microscopic and ultrastructural analysis of GABA-immunoreactive profiles in the monkey spinal cord. J Comp Neurol 300:162-182.

Cervero $F$ (1982) Noxious intensities of visceral stimulation are required to activate viscerosomatic multireceptive neurons in the thoracic spinal cord of the cat. Brain Res 240:350-352.

Cervero F (1983a) Somatic and visceral inputs to the thoracic spinal cord of the cat: effects of noxious stimulation of the biliary system. J Physiol (Lond) 337:51-67.

Cervero F (1983b) Supraspinal connections of neurones in the thoracic spinal cord of the cat: ascending projections and effects of descending impulses. Brain Res 275:251-261.

Cervero F, Connell LA (1984a) Fine afferent fibres from viscera do not terminate in the substantia gelatinosa of the thoracic spinal cord. Brain Res 294:370-374.

Cervero F, Connell LA (1984b) Distribution of somatic and visceral primary afferent fibres within the thoracic spinal cord of the cat. $J$ Comp Neurol 230:88-98.

Cervero F, Tattersall JEH (1985) Cutaneous receptive fields of somatic and viscerosomatic neurons in the thoracic spinal cord of the cat. $J$ Comp Neurol 237:325-332.

Cervero F, Tattersall JEH (1987) Somatic and visceral inputs to the thoracic spinal cord of the cat: marginal zone (lamina I) of the dorsal horn. J Physiol (Lond) 383:383-395.

Chinapen S, Swann JM, Steinman JL, Komisaruk BR (1992) Expression of c-fos protein in lumbosacral spinal cord in response to vaginocervical stimulation in rats. Neurosci Lett 145:93-96.

Ciriello J, Calaresu FR (1983) Central projections of afferent renal fibers in the rat: an anterograde transport study of horseradish peroxidase. J Autonom Nerv Syst 8:273-285.

Craig AD, Heppelmann B, Schaible H-G (1988) The projection of the medial and posterior articular nerves of the cat's knee to the spinal cord. J Comp Neurol 276:279-288.

Davis KD, Dostrovsky JO (1986) Activation of trigeminal brainstem nociceptive neurons by dural artery stimulation. Pain 25:395-401.

Davis KD, Dostrovsky JO (1988a) Responses of feline trigeminal spinal tract nucleus neurons to stimulation of the middle meningeal artery and sagittal sinus. J Neurophysiol 59:648-666.

Davis KD, Dostrovsky JO (1988b) Cerebrovascular application of bradykinin excites central sensory neurons. Brain Res 446:401-406.

Euchner-Wamser I, Sengupta JN, Gebhart GF, Meller ST (1993) Characterization of responses of $\mathrm{T}_{2}-\mathrm{T}_{4}$ spinal cord neurons to esophageal distension in the rat. $\mathrm{J}$ Neurophysiol 69:868-883.

Fang (1961) Cerebral arterial innervations in man. Arch Neurol 4:651656.

Fay $\mathrm{T}$ (1935) The mechanism of headache. Trans Am Neurol Assoc 62:74-77.

Feindel W, Penfield W, McNaughton F (1960) The tentorial nerves and localization of intracranial pain in man. Neurology 10:555-563.

Foreman RD, Hancock MB, Willis WD (1981) Responses of spinothalamic tract cells in the thoracic spinal cord of the monkey to cutaneous and visceral inputs. Pain 11:149-162.

Gokin AP (1970) Synaptic activation of interneurones in the thoracic spinal cord by cutaneous muscle and visceral afferents. Neirofiziologiya $2: 563-572$.

Hancock MB, Rigamonti DD, Bryan RN (1973) Convergence in the lumbar spinal cord of pathways activated by splanchnic nerve and hindlimb cutaneous nerve stimulation. Exp Neurol 38:337-348.

Hancock MB, Foreman RD, Willis WD (1975) Convergence of visccral and cutancous input onto spinothalamic tract cells in the thoracic spinal cord of the cat. Exp Neurol 47:240-248.

Hardebo JE, Arbab M, Suzuki N, Svendgaard NA (1991) Pathways of parasympathetic and sensory cerebrovascular nerves in monkeys. Stroke 22:331-342.

Honda CN (1985) Visceral and somatic afferent convergence onto neurons near the central canal in the sacral spinal cord of the cat. $J$ Neurophysiol 53:1059-1978.

Huber CG (1899) Observations on the innervation of the intracranial vessels. J Comp Neurol 9:1-25.

Hunt SP, Kelly JS, Emson PC, Kimmel JR, Miller RJ, Wu J-Y (1981) An immunohistochemical study of neuronal populations containing neuropeptides or gamma-aminobutyrate within the superficial layers of the rat dorsal horn. Neuroscience 6:1883-1898.
Jacquin MF, Semba K, Egger MD, Rhoades RW (1983) Organization of HRP-labeled trigeminal mandibular primary afferent neurons in the rat. J Comp Neurol 215:397-420.

Jacquin MF, Renehan WE, Mooney RD, Rhoades RW (1986) Structure-function relationships in rat medullary and cervical dorsal horns. I. Trigeminal primary afferents. J Neurophysiol 55:1 153-1 186.

Jacquin MF, Stennett RA, Renehan WE, Rhoades RW (1988) Structure-function relationships in the rat brainstem subnucleus interpolaris. II. Low and high threshold trigeminal primary afferents. J Comp Neurol 267:107-130.

Keller JT, Saunders MC, Beduk A, Jollis JG (1985) Innervation of the posterior fossa dura of the cat. Brain Res Bull 14:97-102.

Krukoff TL, Morton TL, Harris KH, Jhamanda JH (1992) Expression of $c$-fos protein in rat brain elicited by electrical stimulation of the pontine parabrachial nucleus. J Neurosci 12:3582-3590.

Kuo DC, De Groat WC (1985) Primary afferent projections of the major splanchnic nerve to the spinal cord and gracile nucleus of the cat-an anatomical study using transganglionic transport of horseradish peroxidase. J Comp Neurol 231:421-434.

Kuo DC, Nadelhaft I, Hisamitsu T, de Groat WC (1983) Segmental distribution and central projections of renal afferent fibers in the cat studied by transganglionic transport of horseradish peroxidase. J Comp Neurol $216: 162-174$.

Kuo DC, Oravitz JJ, De Groat WC (1984) Tracing of afferent and efferent pathways in the left inferior cardiac nerve of the cat using retrograde and transganglionic transport of horseradish peroxidase. Brain Res 321:111-118.

Lambert GA, Lowy AJ, Boers PM, Angus-Leppan H, Zagami AS (1992) The spinal cord processing of input from the superior sagittal sinus: pathway and modulation by ergot alkaloids. Brain Res 597:321-330.

LaMotte CC, Kapadia SE, Shapiro CM (1991) Central projections of the sciatic, saphenous, median, and ulnar nerves of the rat demonstrated by transganglionic transport of choleragenoid-HRP (B-HRP) and wheat germ agglutinin-HRP (WGA-HRP). J Comp Neurol 311 : 546-562.

Light AR, Kavookjian AM (1988) Morphology and ultrastructure of physiologically identified substantia gelatinosa (lamina II) neurons with axons that terminate in deeper dorsal horn laminae (III-V). J Comp Neurol 267:172-189.

Light AR, Perl E (1979) Spinal termination of functionally identified primary afferent neurons with slowly conducting myelinated fibres. $J$ Comp Neurol 186:133-150.

Light AR, Trevino DL, Perl E (1979) Morphological features of functionally defined neurons in the marginal zone and substantia gelatinosa of the spinal dorsal horn. J Comp Neurol 186:151-172.

Lu J, Hathaway CB, Bereiter DA (1993) Adrenalectomy enhances Fos-like immunoreactivity within the spinal trigeminal nucleus induced by noxious thermal stimulation of the cornea. Neuroscience 54:809-818.

Mayberg M, Langer RS, Zervas NT, Moskowitz MA (1981) Perivascular meningeal projections from cat trigeminal ganglia: possible pathway for vascular headaches in man. Science 10:228-230.

Mayberg MR, Zervas NT, Moskowitz MA (1984) Trigeminal projections to supratentorial pial and dural blood vessels in cats demonstrated by horseradish peroxidase histochemistry. J Comp Neurol 223:46-56.

Menetrey D, Gannon A, Levine JD, Basbaum AI (1989) Expression of c-fos protein in interneurons and projection neurons of the rat spinal cord in response to noxious somatic, articular, and visceral stimulation. J Comp Neurol 285:177-195.

Mense S, Craig AD Jr (1988) Spinal and supraspinal terminations of primary afferent fibers from the gastrocnemius-soleus muscle in the cat. Neuroscience 26:1023-1035.

Milne RJ, Foreman RD, Giesler GJ Jr, Wilis WD (1981) Convergence of cutaneous and pelvic visceral nociceptive inputs onto primate spinothalamic tract neurons. Pain 11:163-183.

Mizumura K, Sugiura Y, Kumazawa T (1993) Spinal termination patterns of canine identified $\mathrm{A}$ - and $\mathrm{C}$ spermatic polymodal receptors traced by intracellular labeling with Phaseolus vulgaris-leucoagglutinin. J Comp Neurol 335:460-468.

Morgan C, Nadelhaft I, de Groat WC (1981) The distribution of visceral primary afferents from the pelvic nerve to Lissauer's tract and the spinal gray matter and its relationship to the sacral parasympathetic nucleus. J Comp Neurol 201:415-440.

Morgan C, deGroat WC, Nadelhaft I (1986a) The spinal distribution 
of sympathetic preganglionic and visceral primary afferent neurons that send axons into the hypogastric nerves of the cat. J Comp Neurol 243:23-40.

Morgan C, Nadelhaft I, deGroat WC (1986b) The distribution within the spinal cord of visceral primary afferent axons carried by the lumbar colonic nerve of the cat. Brain Res 398:11-17.

Moskowitz MA (1984) The neurobiology of vascular head pain. Ann Neurol 16:157-168.

Moskowitz MA, Henrikson BM, Markowitz S, Saito K (1988) Intraand extracraniovascular nociceptive mechanisms and the pathogenesis of head pain. In: Basic mechanisms of headache (Olesen J, Edvinsson L, eds), pp 429-437. Elsevier: Amsterdam.

Moskowitz MA, Nozaki K, Kraig RP (1993) Neocortical spreading depression provokes the expression of $c$-fos protein-like immunoreactivity within trigeminal nucleus caudalis via trigeminovascular mechanisms. J Neurosci 13:1167-1177.

Nadelhaft I, Booth AM (1984) The location and morphology of preganglionic neurons and the distribution of visceral afferents from the rat pelvic nerve: a horseradish peroxidase study. J Comp Neurol 226: 238-245.

Nadelhaft I, Roppolo J, Morgan C, de Groat WC (1983) Parasympathetic preganglionic neurones and visceral primary afferents in monkey sacral spinal cord revealed following application of horseradish peroxidase to pelvic nerve. J Comp Neurol 216:36-52.

Ness TJ, Gebhart GF (1987) Characterization of neuronal responses to noxious visceral and somatic stimuli in the medial lumbosacral spinal cord of the rat. J Neurophysiol 57:1867-1892.

Ness TJ, Gebhart GF (1988) Characterization of neurons responsive to noxious colorectal distension in the $\mathrm{T}_{13}-\mathrm{L}_{2}$ spinal cord of the rat. J Neurophysiol 60:1419-1438.

Ness TJ, Gebhart GF (1989) Characterization of superficial $T_{13}-L_{2}$ dorsal horn neurons encoding for colorectal distension in the rat: comparison with neurons in deep laminae. Brain Res 486:301-309.

Nozaki K, Boccalini P, Moskowitz MA (1992a) Expression of c-foslike immunoreactivity in brainstem after meningeal irritation by blood in the subarachnoid space. Neuroscience 49:669-680.

Nozaki K, Moskowitz MA, Boccalini P (1992b) CP-93,129, sumatriptan, dihydroergotamine block $\mathrm{c}$-fos expression within rat trigeminal nucleus caudalis caused by chemical stimulation of the meninges. Br J Pharmacol 106:409-415.

Nyberg G, Blomqvist A (1984) The central projection of muscle afferent fibres to the lower medulla and upper spinal cord: an anatomical study in the cat with the transganglionic transport method. J Comp Neurol 230:99-109.

O'Connor TP, van der Kooy (1986) Pattern of intracranial and extracranial projections of trigeminal ganglion cells. J Neurosci 6:22002207.

Paxinos G, Watson C (1986) The rat brain in stereotaxic coordinates. San Diego, CA: Academic.

Penfield W (1932) Intracerebral vascular nerves. Arch Neurol Psychiatry 27:30-44.

Penfield W, McNaughton M (1940) Dural headache and innervation of the dura mater. Arch Neurol Psychiatry 44:43-75

Pomeranz B, Wall PD, Weber WV (1968) Cord cells responding to fine myelinated afferents from viscera, muscle and skin. J Physiol (Lond) 199:511-532.

Price DD, Hayashi H, Dubner R, Ruda MA (1979) Functional relationships between neurons of marginal and substantia gelatinosa layers of primate dorsal horn. J Neurophysiol 42:1590-1608.

Ray BS, Wolff HG (1940) Experimental studies on headache: painsensitive structures of the head and their significance in headache. Arch Surg 41:813-856.
Ruch TC (1946) Visceral sensation and referred pain. In: Howell's textbook of physiology (Fulton JF, ed), pp 385-401. Philadelphia: Saunders.

Selzer M, Spencer WA (1969) Convergence of visceral and cutaneous afferent pathways in the lumbar spinal cord. Brain Res 14:331-348.

Sessle BJ, Hu JW, Amano N, Zhong G (1986) Convergence of cutaneous, tooth pulp, visceral, neck and muscle afferents onto nociceptive and non-nociceptive neurones in trigeminal subnucleus caudalis (medullary dorsal horn) and its implications for referred pain. Pain 27:219-235.

Shigenaga $Y$, Chen IC, Suemune S, Nishimori T, Nasution ID, Yoshida A, Sato H, Okamoto T, Sera M, Hosoi M (1986) Oral and facial representation within the medullary and upper cervical dorsal horns in the cat. J Comp Neurol 243:388-408.

Shigenaga Y, Sera M, Nishimori T, Suemune S, Nishimura M, Yoshida A, Tsuru K (1988) The central projection of masticatory afferent fibers to the trigeminal sensory nuclear complex and upper cervical spinal cord. J Comp Neurol 268:489-507.

Steiger HJ, Tew JM, Keller JT (1982) The sensory representation of the dura mater in the trigeminal ganglion of the cat. Neurosci Lett 31:231-236.

Strassman AM, Vos BP (1993) Distribution of fos-like immunoreactivity in the medullary and upper cervical dorsal horn induced by noxious facial stimulation in the rat. J Comp Neurol 331:495-516.

Strassman A, Mason P, Moskowitz M, Maciewicz R (1986) Response of brainstem trigeminal neurons to electrical stimulation of the dura. Brain Res 379:242-250.

Strassman AM, Vos BP, Mineta Y, Naderi S, Borsook D, Burstein R (1993) Fos-like immunoreactivity in the superficial medullary dorsal horn induced by noxious and innocuous thermal stimulation of facial skin in the rat. $\mathbf{J}$ Neurophysiol, in press.

Sugiura Y, Terui N, Hosoya Y (1989) Difference in distribution of central terminals between visceral and somatic unmyelinated $(C)$ primary afferent fibers. J Neurophysiol 62:834-840.

Sugiura $Y$, Terui N, Hosoya $Y$, Tonosaki $Y$, Nishiyama K, Honda T (1993) Quantitative analysis of central terminal projections of visceral and somatic unmyelinated (C) primary afferent fibers in the guinea pig. J Comp Neurol 332:315-325.

Szentagothai J (1984) Neuronal and synaptic arrangement in the substantia gelatinosa Rolandi. J Comp Neurol 122:219-239.

Todd AJ, Sullivan AC (1990) Light microscope study of the coexistence of GABA-like and glycine-like immunoreactivities in the spinal cord of the rat. J Comp Neurol 296:496-505.

Traub RJ, Pechman P, Iadoarola MH, Gebhart GF (1992) Fos-like proteins in the lumbosacral spinal cord following noxious and nonnoxious colorectal distention in the rat. Pain 49:393-403.

Vos BP, Strassman AM, Maciewicz RJ (1991) Effects of loose ligation of the infraorbital nerve on c-fos expression in the medullary dorsal horn of the rat. Soc Neurosci Abstr 17:437.

Williams S, Evan GI, Hunt SP (1990) Changing patterns of c-fos induction in spinal neurons following thermal cutaneous stimulation in the rat. Neuroscience 36:73-81.

Woolf CJ, Fitzgerald M (1983) The properties of neurones recorded in the superficial dorsal horn of the rat spinal cord. J Comp Neurol 221:313-328.

WoolfCJ, Fitzgerald M (1986) Somatotopic organization of cutaneous afferent terminals and dorsal horn neuronal receptive fields in the superficial and deep laminae of the rat lumbar spinal cord. J Comp Neurol 251:517-531.

Yoshida A, Dostrovsky JO, Sessle BJ, Chiang CY (1991) Trigeminal projections to the nucleus submedius of the thalamus in the rat. $J$ Comp Ncurol 307:609-625. 